\title{
DFT THEORETICAL STUDY OF SOME THIOSEMICARBAZIDE DERIVATIVES WITH COPPER
}

\author{
${\text { Tarik } \text { Attar }^{1}, 2, \otimes, \text { Boulanouar Messaoudi }}^{1,3}$, Naceur Benhadria ${ }^{1}$
}

https://doi.org/10.23939/chcht14.01.020

\begin{abstract}
A theoretical study of the detection limit concept of copper traces in aqueous solution by using two thiosemicarbazides derivatives as ligands: 4-ethyl-3thiosemicarbazide and thiosemicarbazide has been thoroughly investigated. The study was carried out experimentally by adsorptive stripping voltammetry. The quantum chemistry calculations, carried out at the 6$31 \mathrm{G}(\mathrm{d})$ basis set in conjunction with local spin density approximation method (LSDA), implemented in Gaussian 09 program package, show the existence of a very strong relationship between the total energy of copper complexes and the detection limit; thus, the more stable complex has the lower detection limit value. The obtained results are in a good agreement with the experimental findings.
\end{abstract}

Keywords: thiosemicarbazide, detection limit, selectivity, Fukui indices, DFT calculations.

\section{Introduction}

Trace elements are defined as essential elements in small quantities. Their lack or excess may result in malfunctioning of human and animal body. These trace elements may have direct severe consequences on both the metabolic and physiologic processes of the organism and lead to fatal diseases [1]. For instance, copper is one of the most important trace elements with biological significance to the cardiovascular disease patient [2]. The ability of copper to easily attach and accept electrons explains its importance in oxidative reduction processes and in disposing and removing free radicals from the organism.

Electrochemical techniques are of considerable importance in analysis due to their high degree of

\footnotetext{
${ }^{1}$ Superior School of Applied Sciences, P.O. Box 165 RP, Tlemcen, 13000, Algeria

${ }^{2}$ Laboratory ToxicoMed, University of Abou Bekr Belkaïd, B.P.119, Tlemcen, 13000, Algeria

${ }^{3}$ Laboratory of Applied Thermodynamics and Molecular Modeling, Department of Chemistry,

University of Abou Bekr Belkaïd, B.P. 119, Tlemcen, 13000, Algeria

att_tarik@yahoo.fr

(c) Attar T., Massaoudi B., Benhadria N., 2020
}

sensitivity, accuracy, precision and selectivity, as well as large linear dynamic range, with relatively low-cost instrumentation [3, 4]. Their applications cover many fields such as environment, metal industry, pharmaceutics, clinical medicine and food industry. The concept of continuously changing the applied potentials to the electrode-solution interface and the resulting measured current is the basic principle of the most useful electroanalytical techniques [5]. Among the latter, polarography is a special case of voltammetry where the working electrode is a dropping mercury electrode. This technique is based on current measurement as a function of voltage [6]. Electrochemical stripping analysis is the most popular analytical technique used for the determination of trace element species. The stripping voltammetry technique involves two main steps. The first step is a controlled potential electrolysis sufficient to deposit the analyte on the electrode. The second step consists of the application of a voltage scan to the electrode that causes an electrolytic dissolution. The current generated by voltammetric stripping is directly proportional to the concentration of the analyte in the solution. Adsorptive stripping voltammetry is quite similar to anodic and cathodic stripping voltammetry methods [7]. This technique can be employed in the trace analysis of a wide variety of organic and inorganic analytes [8].

In electroanalysis, there has been a considerable interest of the detection limit. Nowadays, voltammetry represents a refined technique that offers wide limits of detection and is used for trace analysis [9]. When a ligand comes to coordinate with a metal ion, there happens a great change in the global energy between the ligand and the metal complex. In the framework of the DFT method, the energies of the frontier molecular orbitals, the energy band gap, electronegativity, chemical potential, global hardness, and global softness are important tools to understand the reason for low detection limit in electroanalysis. In the present paper we use the DFT method to provide a relevant insight into molecular electronic properties of organometallic complexes, their formation and stability. As far as we have been able to 
ascertain, the DFT study of metal trace analysis by polarography technique and, in particular, the study of the concept of the limit of detection has not been reported. This concept has been defined as an analyte concentration that yields a signal in the measurement instrument which is significantly different from that obtained for the blank $[10,11]$.

The study includes the DFT calculations of copper reaction with two thiosemicarbazides (TSC) derivatives ligands in a manner to elucidate the importance of the relationship between the stability of the complex and the detection limit in electroanalysis which can provide the scientific researches with a novel way for prediction and can be considered as a complementary experimental result. As a comparative study between our recent publication work on copper complex with 4-ethyl-3-thiosemicarbazide (ETSC) realized in the same conditions of another research on copper-thiosemicarbazide complex, a detection limit of $0.001 \mathrm{ng} \cdot \mathrm{ml}^{-1}$ was measured lower than when thiosemicarbazide was used as ligand $\left(0.007 \mathrm{ng} \cdot \mathrm{ml}^{-1}\right)$ $[12,13]$.

Let us consider here two steps involved in the formation of $\mathrm{Cu}\left(\mathrm{CH}_{5} \mathrm{~N}_{3} \mathrm{~S}\right)_{2}{ }^{2+}$ ion:

Step 1: $\mathrm{Cu}^{2+}+\mathrm{CH}_{5} \mathrm{~N}_{3} \mathrm{~S} \rightarrow \mathrm{Cu}\left(\mathrm{CH}_{5} \mathrm{~N}_{3} \mathrm{~S}\right)^{2+}$

Step 2: $\mathrm{Cu}\left(\mathrm{CH}_{5} \mathrm{~N}_{3} \mathrm{~S}\right)^{2+}+\mathrm{CH}_{5} \mathrm{~N}_{3} \mathrm{~S} \rightarrow \mathrm{Cu}\left(\mathrm{CH}_{5} \mathrm{~N}_{3} \mathrm{~S}\right)_{2}{ }^{2}$

In the same manner, we can consider two steps involved in the formation of $\mathrm{Cu}\left(\mathrm{C}_{3} \mathrm{H}_{9} \mathrm{~N}_{3} \mathrm{~S}\right)_{2}{ }^{2+}$ ion:

Step 1: $\mathrm{Cu}^{2+}+\mathrm{C}_{3} \mathrm{H}_{9} \mathrm{~N}_{3} \mathrm{~S} \rightarrow \mathrm{Cu}\left(\mathrm{C}_{3} \mathrm{H}_{9} \mathrm{~N}_{3} \mathrm{~S}\right)^{2+}$

$\rightarrow \mathrm{Cu}\left(\mathrm{C}_{3} \mathrm{H}_{9} \mathrm{~N}_{3} \mathrm{~S}\right)_{2}{ }^{2+}$

Step 2: $\mathrm{Cu}\left(\mathrm{C}_{3} \mathrm{H}_{9} \mathrm{~N}_{3} \mathrm{~S}\right)^{2+}+\mathrm{C}_{3} \mathrm{H}_{9} \mathrm{~N}_{3} \mathrm{~S} \rightarrow$

\section{Theoretical}

\subsection{Materials and Methods}

The present study has been done using the Density Functional Theory (DFT) with the LSDA method [14], in conjunction with 6-31G(d) basis set, implemented in Gaussian 09 program package [15]. Density Functional Theory (DFT) is one of the most commonly used quantum mechanical method. This method is based on determining functionals that relate the electronic density to the energy. Full geometry optimizations followed by frequency calculations at the same level of theory were performed for all the stationary points. The Fukui indices were calculated using the FDA approximation. We noted that the cationic and anionic systems, required in the calculations of local indices, were kept at the same geometry of the neutral system. The electronic populations were computed using both MK (Merz-SinghKollman) and NPA (natural population analysis) [16].

\subsection{Global Reactivity Indices}

Rigorous definitions of well-known qualitative chemical concepts such as electronegativity $\chi$ [17] and hardness $\eta$ [18] have been given from the standpoint of conceptual density functional theory (DFT) $[19,20]$. The general definition of electronegativity is cited as the negative of chemical potential [21]. For an N-electron system with total energy $E$ and external potential, it is defined as:

$$
\chi=-\mu=-\left(\frac{\partial E}{\partial N}\right)_{v(r)}
$$

where $\mu$ is the Lagrange multiplier associated with the normalization constraint of DFT $[19,22]$.

Thus, hardness $\eta$ [23] is the corresponding second derivative:

$$
\eta=\left(\frac{\partial^{2} E}{\partial N}\right)_{v(r)}=\left(\frac{\partial \mu}{\partial N}\right)_{v(r)}
$$

Using a finite difference method, $\chi$ and $\eta$ may be calculated as [19]:

$$
\begin{gathered}
\chi=\frac{I+A}{2} \\
\eta=I-A
\end{gathered}
$$

where $I$ and $A$ are the ionization potential and electron affinity, respectively.

On the basis of Koopmans' theorem [24], the latter equations can be developed as:

$$
\begin{aligned}
& \chi=\frac{\varepsilon_{\text {HOMO }}+\varepsilon_{\text {LUMO }}}{2} \\
& \eta=\varepsilon_{\text {LUMO }}-\varepsilon_{\text {HOMO }}
\end{aligned}
$$

where $\varepsilon_{\mathrm{HOMO}}$ and $\varepsilon_{\text {LUMO }}$ are the energies of the highest occupied and lowest unoccupied molecular orbitals, respectively.

Parr et al. [19] defined the electrophilicity index as:

$$
\omega=\frac{\mu^{2}}{2 \eta}
$$

This quantity is basically a measure of the electrophilic power of a given system. Domingo's group has proved, after some previously given and studied definitions [25], that the nucleophilic character of a molecule is in good conjunction with the feasibility to remove electron-density. Thus, the nucleophilicity is then attributed as the negative value of the gas phase ionization potentials $I P$ :

$$
N=-I P
$$

Consequently, high (low) nucleophilicities correspond to low (high) ionization potentials.

To put in evidence a practical nucleophilicity descriptor, Domingo's group used Kohn-Sham's highest occupied molecular orbital (HOMO) energies obtained 
giving rise to a relative empirical nucleophilicity index $N$ defined as $[25,26]$ :

$$
N=\varepsilon_{\text {HOMO }(\mathrm{Nu})}-\varepsilon_{\text {HOMO(TCE) }}
$$

This nucleophilicity scale is referred to tetracyanoethylene (TCE) taken as a reference since it presents the lowest HOMO energy [25].

\subsection{Local Reactivity Indices}

Local quantities describe the reactivity of each site in a molecule toward a given attack. For instance, Fukui function is defined as [27]:

$$
f(r)=\left[\frac{\partial \rho(r)}{\partial N}\right]_{v(r)}=\left[\frac{\delta \mu}{\delta v(r)}\right]_{N}
$$

where $\rho(r)$ is the electronic density of a system, $N$ is the number of electrons and $v(r)$ is a constant external potential.

Yang and Mortier [28] introduced the condensed form of the Fukui function. Their calculation method is based on the finite difference approximation (FDA) resulting to the formula:

$$
\text { Nucleophilic attack } f_{k}^{+}=\left[\rho_{k}(N+1)-\rho_{k}(N)\right]
$$

$$
\text { Electrophilic attack } f_{k}^{-}=\left[\rho_{k}(N)-\rho_{k}(N-1)\right]
$$

where $\rho_{k}(N), \rho_{k}(N-1)$ and $\rho_{k}(N+1)$ are the gross electronic populations of the site $k$ in neutral, cationic, and anionic systems, respectively.

The charges can be calculated using the population analysis currently used (Mulliken, natural, electrostatic, etc.). Eqs. (11a) and (11b) have been applied to a variety of systems in order to look for reactivity trends $[29,30]$.

\section{Results and Discussion}

Thiosemicarbazide compounds are of particular interest since they hold three atoms of nitrogen and one atom of sulphur in each molecule. The complexation phenomenon on the metal (copper) ion is closely related to these heteroatoms.

Our aim in this work is to give a deeper insight of the substituent effect on the detection limit and its relationship to the stability of the studied compounds (Fig. 1) by means of DFT-based reactivity indices.

In order to rationalize the local reactivity, we have calculated the Fukui indices $f_{k}^{-}$using the labelling shown in Fig. 2.

The results are given in Table 1 and 2. The Fukui indexes, $f_{k}^{-}$, corresponding to electrophilic attack are calculated using two types of population analysis: MerzSingh-Kollman (MK) and natural population analyses (NPA) to have a good view of the most reactive sites of the studied compounds.

The analysis of the local nucleophilicity indices given in Table 2 shows that the central nitrogen atom and the sulphur atom for both cases of thiosemicarbazide derivatives are characterized by the highest values of the local nucleophilicity indices. As a result, $\mathrm{N}, \mathrm{O}$, and $\mathrm{C}$ atoms of two studied molecules are the most reactive centers, which involve a greater ability to bind to the metal surface. Consequently, the analysis based on the static DFT-based indices, correctly predicts the regioselectivity of these complexes in a good agreement with experiments.

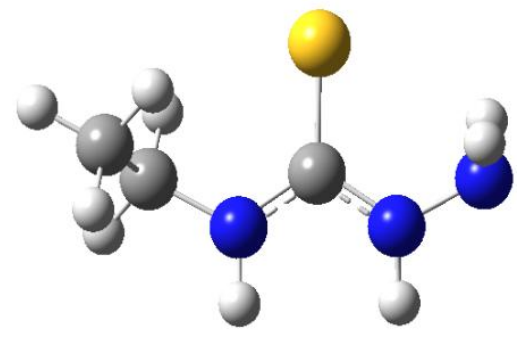

b)

Fig. 1. Molecular structures of TSC (a) and ETSC (b)

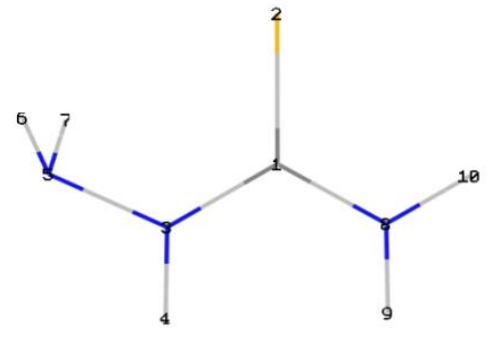

a)

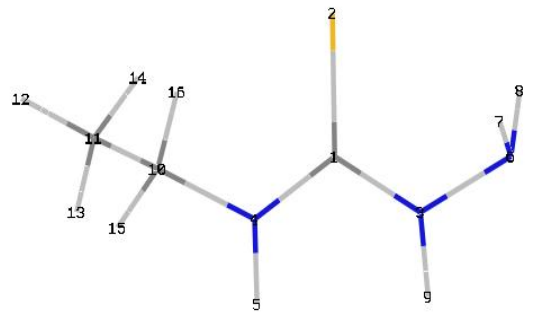

b)

Fig. 2. Atoms labelling for TSC (a) and ETSC (b) 
Fukui $(f)$ and DFT-based $\left(N_{k}\right)$ indices of the selected atoms for the thiosemicarbazide using NPA population analyses at $\mathrm{HF} / 3-21 \mathrm{G}$ level of theory

\begin{tabular}{|c|c|c|c|}
\hline Atom $k$ & $f^{+}$ & $f$ & $N_{k}$ \\
\hline C1 & 0.30571 & -0.06124 & -0.02723 \\
\hline S2 3 & 0.31910 & 0.75428 & 0.33538 \\
\hline N5 & 0.02841 & 0.05756 & 0.02559 \\
\hline N8 & 0.02874 & 0.02703 & 0.01202 \\
\hline
\end{tabular}

Table 2

Fukui $(f)$ and DFT-based $\left(N_{k}\right)$ indices of the selected atoms for 4-ethyl-3-thiosemicarbazide using NPA population analyses at $\mathrm{HF} / 3-21 \mathrm{G}$ level of theory

\begin{tabular}{|c|c|c|c|}
\hline Atom $k$ & $f^{\prime}$ & $f$ & $N_{k}$ \\
\hline C1 & 0.30530 & -0.04350 & -0.02163 \\
\hline S2 & 0.30029 & 0.79170 & 0.39360 \\
\hline N3 & 0.02649 & 0.02075 & 0.01032 \\
\hline N4 & 0.04277 & 0.03670 & 0.01825 \\
\hline N6 10 & 0.02662 & 0.03272 & 0.01627 \\
\hline C11 & -0.01812 & -0.01573 & -0.00782 \\
\hline
\end{tabular}

HOMO

LUMO

HOMO-1

TSC
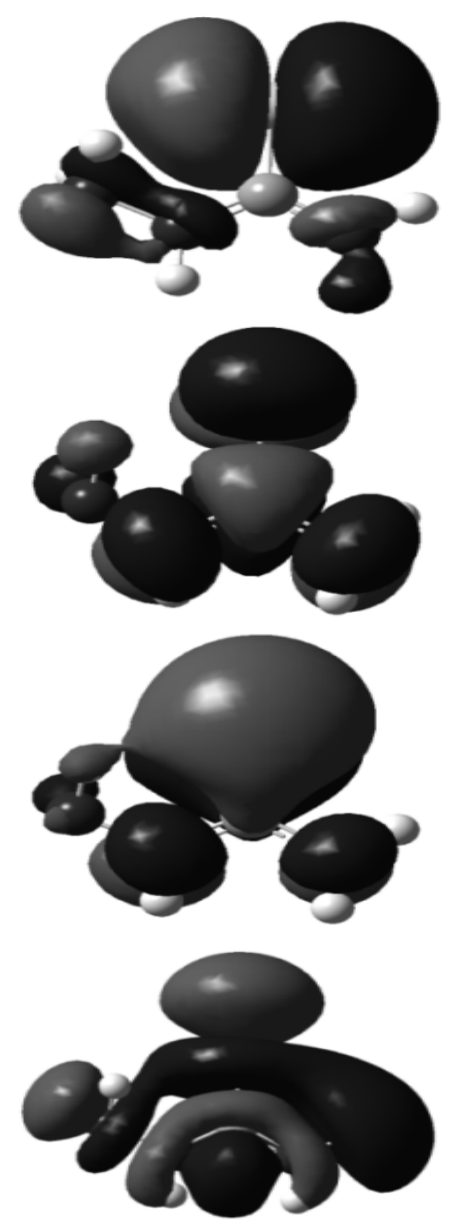

ETSC
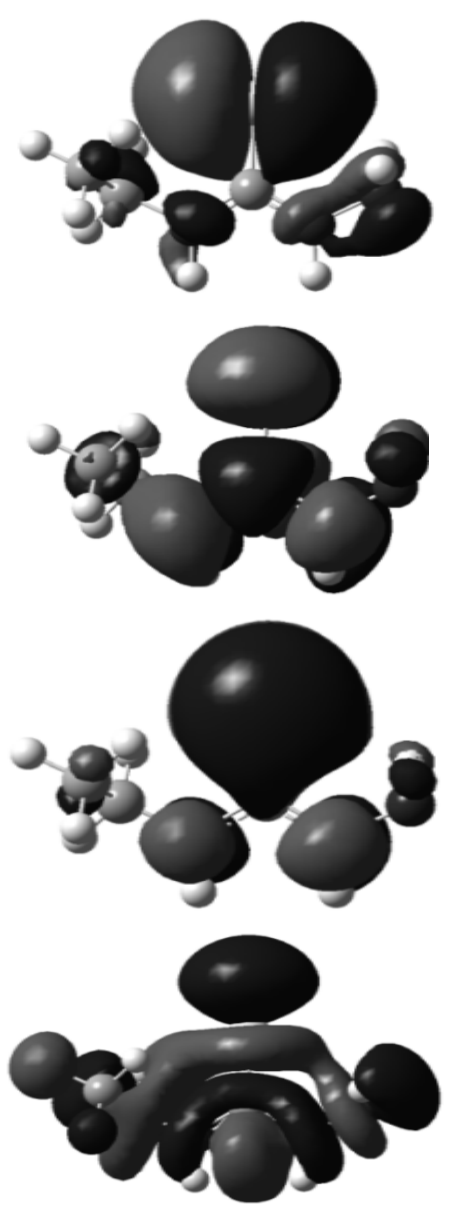

Fig. 3. Calculated HOMO, HOMO-1, LUMO and LUMO+1 molecular orbitals of the studied molecules at the LSDA/6-31G level of theory 
On the other hand, the distribution of electron density of frontier molecular orbitals of the thiosemicarbazide derivatives is crucial when talking about such reactions. The HOMO does not provide a good proof and evidence of this region reactivity. However, the HOMO-1 (Fig. 3) is important in the area containing five nitrogens. Its visualization shows a large distribution on the sulfur atom followed by the other nitrogen atoms. Therefore, we can conclude that this area is the region of reactive centers that transfer electrons from sulphur and nitrogen atoms to the copper surface.

The electronegativity $\chi$ has been proven to be a useful parameter in chemical reactivity theory. When two systems, in this case, copper and the thiosemicarbazide derivatives are joined, electrons will flow from the lower $\chi$ value (thiosemicarbazide derivatives) to the higher $\chi$ value $(\mathrm{Cu})$ until the equalization of chemical potentials. TSC presents a slightly larger $\chi$ value of $2.144 \mathrm{eV}$ with respect to 4-ethyl-3-thiosemicarbazide, that has only $2.136 \mathrm{eV}$ (Table 3).

The electrophilicity index $\omega$ is another important parameter that indicates the tendency of the molecule to accept electron(s). We note here (Table 3) that two studied thiosemicarbazide derivatives show the electrophilicity value of $0.18 \mathrm{eV}$. Thus, the unoccupied $d$-orbitals of the $\mathrm{Cu}$ atom can accept electrons from these molecules to form a coordinate bond. The studied molecule can accept electrons from the $\mathrm{Cu}$ atom with its anti-bonding orbitals to form a back-donating bond. These donation and backdonation processes strengthen the interaction of thiosemicarbazide derivatives with the metal ion. In addition, both the theoretical and experimental trends go in concomitant.

The comparative study of the relative stabilities of the formed complexes, i.e. copper-di-TSC and copper-diETSC (Fig. 4) provides a clear idea about the relationship between the detection limit and the complex stability. From the energy values presented in Fig. 4 and Table 4, we can see that the copper-di-4-ETSC is more stable energetically and thermodynamically than copper-di-TSC. In addition, the detection limit is 0.007 and $0.001 \mathrm{ng} \cdot \mathrm{ml}^{-1}$ for copper-di-TSC and copper-di-ETSC, respectively. So, we can see that the more stable the complex, the less its detection limit.

Table 3

HOMO and LUMO energies, global reactivity indices $\mu, \eta, \omega$ and $N$ for the thiosemicarbazide and 4-ethyl-3-thiosemicarbazide at HF/3-21G level of theory

\begin{tabular}{|c|c|c|c|c|c|c|c|}
\hline Substrate & HOMO $(\mathrm{au})$ & LUMO $(\mathrm{au})$ & $\mu, \mathrm{a} . \mathrm{u}$ & $\eta, \mathrm{a} . \mathrm{u}$ & $\omega, \mathrm{eV}$ & $N$, eV & Gap, a.u \\
\hline TSC & -0.3188 & 0.1612 & -0.0788 & 0.4799 & 0.18 & 0.44 & 0.4800 \\
\hline ETSC & -0.3168 & 0.1598 & -0.0785 & 0.4766 & 0.18 & 0.50 & 0.4766 \\
\hline
\end{tabular}

Copper-di-TSC

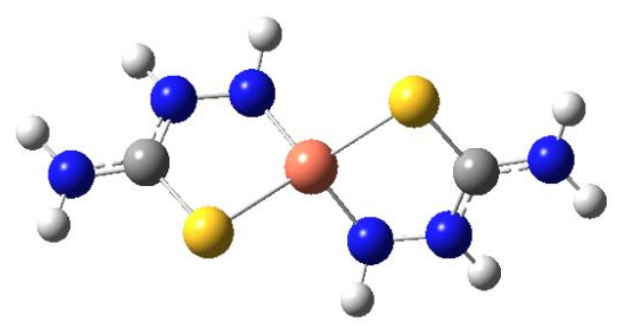

$E=-2826.02$ a.u
Copper-di-ETSC

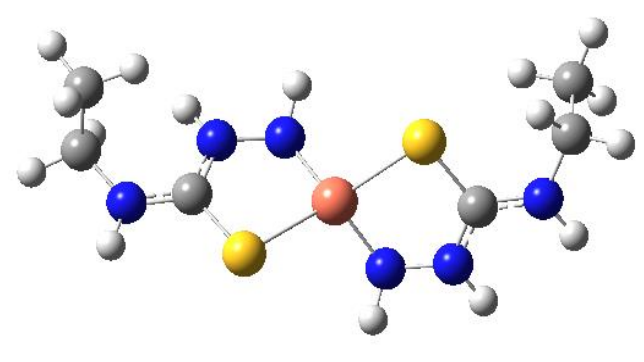

$E=-2981.57$ a.u

Fig. 4. Molecular structures of copper-di-TSC and copper-di-ETSC complexes at the LSDA/6-31G level of theory

Table 4

Values of energy, enthalpy, free energy, and entropy calculated in the gas phase at LSDA/3-21G level of theory

\begin{tabular}{|c|c|c|c|c|}
\hline & $E$, a.u & $H$, a.u & $G$, a.u & $S, \mathrm{~J} \cdot \mathrm{K}^{-1} \cdot \mathrm{mol}^{-1}$ \\
\hline $\mathrm{Cu}^{2+}$ & -1630.20 & -1630.20 & -1630.22 & 166.03 \\
\hline TSC & -598.34 & -598.25 & -598.29 & 324.95 \\
\hline ETSC & -676.11 & -675.97 & -676.01 & 378.92 \\
\hline Copper di-TSC & -2826.02 & -2825.88 & -2825.93 & 484.25 \\
\hline Copper di-ETSC & -2981.57 & -2981.30 & -2981.37 & 595.57 \\
\hline
\end{tabular}


As it is indicated in Table 4, the entropy value of copper di-ETSC is somehow larger than that of copper diTSC. Thus, the former complex shows a high disorder with respect to the latter due to the substituent effect of ethyl. This clearly proves that the stability of complexes dependss on the nature of central atom and ligands [31].

\section{Conclusions}

In the present study, we have performed some quantum chemical calculations at LSDA/6-31G(d) method on two thiosemicarbazide derivatives to investigate the structural and electronic properties, on theone hand, to elucidate the reactivity and selectivity of the molecules centers and on the other hand, to find a relationship between the detection limit and the energetic stability of the formed complexes. We have found that the selective centers are N, S and central $\mathrm{C}$ of the closing region (when bonding with copper) for both the thiosemicarbazide and 4-ethyl-3-thiosemicarbazide where the atom $\mathrm{S}$ presents the highest ability for the copper electrophilic attack. The calculated energies show that the copper-di-ETSC is more stable energetically and thermodynamically than the copper-di-TSC, which is in the same trend of their respective detection limits.

\section{Acknowledgements}

The researcher team would like to express their thanks to the Ministry of Higher Education and Scientific Research of the Algerian Government and Superior School of Applied Sciences for their fruitful support.

\section{References}

[1] Bhattacharya P., Misra S., Hussain M.: Scientifica, 2016, 2016, 1. https://doi.org/10.1155/2016/5464373

[2] Attar T., Harek Y., Larabi L.: Mediterr. J. Chem., 2014, 2, 691.

https://doi.org/10.13171/mjc.2.6.2014.22.02.30

[3] Mojtaba H., Ahmad R., Mohammad Y.: Sens. Actuator. B, 2011, 160, 121. https://doi.org/10.1016/j.snb.2011.07.022

[4] Xing X., Liu S., Yu J. et al.: Biosens. Bioelectron., 2012, 31, 277. https://doi.org/10.1016/j.bios.2011.11.012

[5] Farghaly O., Abdel-Hameed R., Abu-Nawwas A.: Int. J.

Electrochem. Sci., 2014, 9, 3287.

[6] Abu-Shandi K.: Chem. Chem. Technol., 2018, 12, 147.

https://doi.org/10.23939/chcht12.02.147

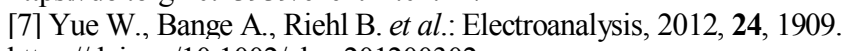
https://doi.org/10.1002/elan.201200302

[8] Yardım Y., Gülcan M., Sentürk Z.: Food Chem., 2013, 141, 1821. https://doi.org/10.1016/j.foodchem.2013.04.085

[9] Idris A., Mabuba N., Arotiba O.: J. Electroanal. Chem., 2015, 758, 7. https://doi.org/10.1016/j.jelechem.2015.10.009

[10] Ardila J., Oliveira G., Medeiros R. et al.: J. Electroanal. Chem., 2013, 690, 32. https://doi.org/10.1016/j.jelechem.2012.11.038

[11] Illuminati S., Annibaldi A., Truzzi C. et al.: J. Electroanal.

Chem., 2015, 755, 182.

https://doi.org/10.1016/j.jelechem.2015.07.023

[12] Abbasi S., Khani H., Tabaraki R.: Food Chem., 2010, 123, 507.

https://doi.org/10.1016/j.foodchem.2010.03.043
[13] Attar T., Harek Y., Larabi L.: J. Korean. Chem. Soc., 2013, 57, 568. https://doi.org/10.5012/jkcs.2013.57.5.568

[14] Frisch M., Trucks G., Schlegel H. et al.: Gaussian 09, Revision A.02, Gaussian Inc Wallingford CT, 2009, 34.

[15] Domingo L., Aurell M., Perez P. et al.: Tetrahedron, 2002, 58, 4417. https://doi.org/10.1016/S0040-4020(02)00410-6

[16] Besler B., Merz K., Kollman P.: J. Comput. Chem., 1990, 11, 431. https://doi.org/10.1002/jcc.540110404

[17] Sen K., Jorgenson C. (Eds.): Electronegativity, Structure and Bonding, Vol. 66, Springer Verlag, Berlin, Heidelberg, New York, London, Paris, Tokyo 1987.

[18] Pal S., Roy R., Chandra R.: J. Phys. Chem., 1994, 98, 2314.

https://doi.org/10.1021/j100060a018

[16] Parr R., von Szentpaly L., Liu S.: J. Am. Chem. Soc., 1999, 121, 1922. https://doi.org/10.1021/ja983494x

[20] Geerlings P., De Proft F., Langenaeker W.: Chem. Rev., 2003,

103, 1793. https://doi.org/10.1021/cr990029p

[21] Parr R., Donnelly R., Levy M. et al.: J. Chem. Phys., 1978, 68, 3801. https://doi.org/10.1063/1.436185

[22] Kohn W., Sham L.: J. Phys. Rev. A, 1965, 140, 1133.

https://doi.org/10.1103/PhysRev.140.A1133

[23] Parr R.G., Pearson R.G.: J. Am. Chem. Soc., 1983, 105, 7512.

DOI: $10.1021 / \mathrm{ja} 00364 \mathrm{a} 005$

[24] Koopmans T.: Physica, 1933, 1, 104.

https://doi.org/10.1016/S0031-8914(34)90011-2

[25] Jaramillo P., Domingo L., Chamorro E. et al.: J. Mol. Struct.

Theochem., 2008, 865, 68.

https://doi.org/10.1016/j.theochem.2008.06.022

[26] Contreras R., Andres J., Safont V. et al.: J. Phys. Chem. A., 2003, 107, 5588. https://doi.org/10.1021/jp0302865

[27] Parr R., Yang W.: J. Am. Chem. Soc., 1984, 106, 4049.

https://doi.org/10.1021/ja00326a036

[28] Yang W., Mortier W.: J. Am. Chem. Soc., 1986, 108, 5708. https://doi.org/10.1021/ja00279a008

[29] De Proft F., Martin J., Geerlings P.: Chem. Phys. Lett., 1996, 256, 400. https://doi.org/10.1016/0009-2614(96)00469-1

[30] Nguyen L., Ngoc L., De Proft F. et al.: J. Am. Chem. Soc., 1999, 121, 5992. https://doi.org/10.1021/ja983394r

[31] Rakitskaya T., Truba A., Radchenko E. et al.: Chem. Chem.

Technol., 2018, 12, 1. https://doi.org/10.23939/chcht12.01.001

Received: September 25, 2018 / Revised: October 10, 2018 / Accepted: December 28, 2018

\section{ТЕОРЕТИЧНІ ДОСЛІДЖЕННЯ ДЕЯКИХ ПОХІДНИХ ТІОСЕМІКАРБАЗИДУ 3 МІДДЮ З ВИКОРИСТАННЯМ ТЕОРІЇ ФУНКЦОНАЛА ГУСТИНИ}

Анотація. Проведені теоретичні дослідження виявлення слідів міді у водному розчині з використанням двох похідних тіосемікарбазидів як лігандів: 4-етил-3-тіосемікарбазиду $i$ тіосемікарбазиду. Експериментальні дослідження проведені за допомогою адсорбиійної інверсійної вольтамперометрії. Квантово-хімічні розрахунки виконані на базі 6-31G(d) у поєднанні з методом апроксимачії локальної спінової щільності та реалізовані в пакеті програм Gaussian 09. Доведено наявність значної залежності між сумарною енергією комплексів міді та межею виявлення: чим стабільніший комплекс, тим нижча межа виявлення. Отримані результати добре узгоджуються з експериментальними висновками.

Ключові слова: тіосемікарбазид, межа виявлення, селективність, індекси Фукуї, теорія функиіонала густини. 